\title{
loncopy: an R Shiny app to call copy number alterations in targeted NGS data
}

Jan Budczies ${ }^{1,4^{*}}$ (D) Nicole Pfarr ${ }^{2,4}$, Eva Romanovsky $^{1}$, Volker Endris $^{3}$, Albrecht Stenzinger $^{3,4}$ and Carsten Denkert ${ }^{1,4}$

\begin{abstract}
Background: Somatic copy number alterations (CNAs) contribute to the clinically targetable aberrations in the tumor genome. For both routine diagnostics and biomarkers research, CNA analysis in a single assay together with somatic mutations is highly desirable.

Results: loncopy is a validated method and easy-to-use software for CNA calling from targeted NGS data. Copy number and significance of CNA are estimated for each gene in each sample. Copy number gains and losses are called after multiple testing corrections controlling FWER or FDR.

Conclusions: Ioncopy facilitates calling of CNAs in a cohort of tumors tissues with or without using normal (germline) DNA controls.
\end{abstract}

Keywords: Copy number alterations, NGS, Amplicon sequencing, R Shiny

\section{Background}

In addition to conventional somatic mutations such as point mutations and small indels, clinically relevant genetic alterations in tumors include large-scale somatic aberrations such as translocations and copy number alterations (CNAs). As classical example of an actionable CNA, testing for HER2 amplifications revolutionized breast cancer care, since the FDA approved Herceptin for the treatment of metastatic and later for early breast cancer [1]. Both the numbers of patients and genes commonly tested for amplifications in routine diagnostics keep continuously growing. For example, amplified HER2, MET and FGFR1 are potential drug targets in lung and other cancers [2-4]. MDM2 is used in diagnostics of liposarcoma [5] and has recently been described to be associated with hyperprogression of metastatic cancer after immune therapy [6].

Gene amplifications are usually tested using in situ hybridization (ISH) based assays. On the other hand, targeted NGS, e.g. using the IonTorrent S5 or the Illumina MiSeq platform, is the today's mainstay for routine testing of mutations. Therefore, integrating mutation analysis and

\footnotetext{
*Correspondence: jan.budczies@charite.de

${ }^{1}$ Institute of Pathology, Charité Universitätsmedizin Berlin, Berlin, Germany ${ }^{4}$ German Cancer Consortium (DKTK), Berlin, Munich and Heidelberg partner sites, Germany

Full list of author information is available at the end of the article
}

CNA detection in a single assay would be highly desirable for both routine diagnostics and biomarker research.

Calling of CNAs from targeted sequencing data has shown to be feasible by several authors after publication of the first larger study [7]. Sensitivities obtained for HER2 amplification calling in breast cancer range between $89 \%$ and $93 \%$ at specificities between $98 \%$ and $100 \%$ [8-10]. Methodically, all approaches use DNA sequencing coverages as input and rely on calling coverage outliers after data normalization. Most of the current algorithm requires sequencing of paired tumor and normal (germline) DNA samples [11] or utilize a normal DNA references for normalization [10, 12, 13]. Outlier detection relies on simple thresholding $[7,9,14]$ or more sophisticated methods of $p$-value estimation $[8,10]$ or bootstrap based estimation of confidence intervals [15].

Ioncopy is a method for calling of CNAs from targeted NGS data validated before [8], which can be run in two modes either using only the cohort of interest as input (and outlier detection by internal statistics) or making use of an additional reference cohort (e.g. of normal tissue or blood samples). The extended version presented here includes a GUI for easy data upload and straightforward CNA analysis.

\section{Implementation}

Ioncopy is an R Shiny app that can be operated without knowledge of the $\mathrm{R}$ programming language [16]. Input file

(c) The Author(s). 2018 Open Access This article is distributed under the terms of the Creative Commons Attribution 4.0 International License (http://creativecommons.org/licenses/by/4.0/), which permits unrestricted use, distribution, and reproduction in any medium, provided you give appropriate credit to the original author(s) and the source, provide a link to the Creative Commons license, and indicate if changes were made. The Creative Commons Public Domain Dedication waiver (http://creativecommons.org/publicdomain/zero/1.0/) applies to the data made available in this article, unless otherwise stated. 
format, analysis parameters and the formats of the output files are described in the user manual (Additional file 1).

Amplicon coverages of the cohort of interest (and optionally additionally of a reference cohort) are used as input. Coverage data are uploaded as one or several tab-separated files. Data procession and CNA calling are performed as follows: 1. Sample normalization: Each sample is scaled with the median of its amplicon coverages. 2. Amplicon normalization: If reference coverages are available, each amplicon is scaled by its median coverage in the reference data. If no reference coverages are available, each amplicon is scaled by its median coverage in the target data. Multiplication by two (corresponding to two alleles) is performed to obtain estimates of copy numbers (CNs). 3. Significance assessment for CNAs in each amplicon and each sample: First, a normal distribution centered around $\mathrm{CN}=2$ with variance estimated from the median average deviation (mad) is fitted to the distribution of $\mathrm{CNs}$ for each amplicon. Then, a $p$-value is calculated for each amplicon and each sample assessing the degree of being an outlier to normal distribution. 4. In the mode "gene-wise", the $p$-values of all amplicons interrogating a gene are summarized to a single p-value using Fisher's method [17] and CNs are summarized by taking the amplicon average. 5. Either, no multiple testing corrections, multiple testing corrections with respect to samples, multiple testing corrections with respect to genes or multiple testing corrections with respect to samples and genes are done. Then, $p$-values are corrected to control either family-wise error rate (FWER) or false discovery rate
(FDR) using the Bonferroni or the Benjamini-Hochberg method respectively. 6. CNAs (gains and losses) are called when passing the significance threshold (corrected $p<0$. 05).

The intra-gene inconsistency (IGI) is a quality measure for a sample $s$ that is calculated from its amplicon coverages $\mathrm{CN}(a, s)$ by

$$
\operatorname{IGI}(s)=\sum_{g \in G} \sqrt{\frac{1}{n(g)-1} \sum_{a \in A(g)}[\mathrm{CN}(a, s)-\mathrm{CN}(g, s)]^{2}} .
$$

Therein, $G$ denotes the set of all genes, $n(g)$ the number and $A(\mathrm{~g})$ the set of amplicons interrogating the gene $g . \mathrm{CN}(g$, $s$ ) is the $\mathrm{CN}$ estimate for gene $g$ calculated as average of $\mathrm{CN}(a, s)$ over the amplicons $a$ interrogating the gene $g$. Higher IGI corresponds higher intra-gene variance of $\mathrm{CNs}$ and is a technical issue related to inferior sample quality in the most cases. The IGI for each sample is included in the sample-centered output file of CNAs (CNAs samples: list). Hierarchical clustering in the heatmap display is performed using Manhattan distance and the average linkage method.

\section{Results and discussion}

As use case, we analyze 184 breast carcinoma sequenced on an Ion Torrent PGM using a 154-amplicon-panel and published before [8]. After loading of the ioncopy package and starting of the app by runIoncopy(), data upload and analysis can be performed GUI-based and without knowledge of the $\mathrm{R}$ language (Fig. 1). First, the

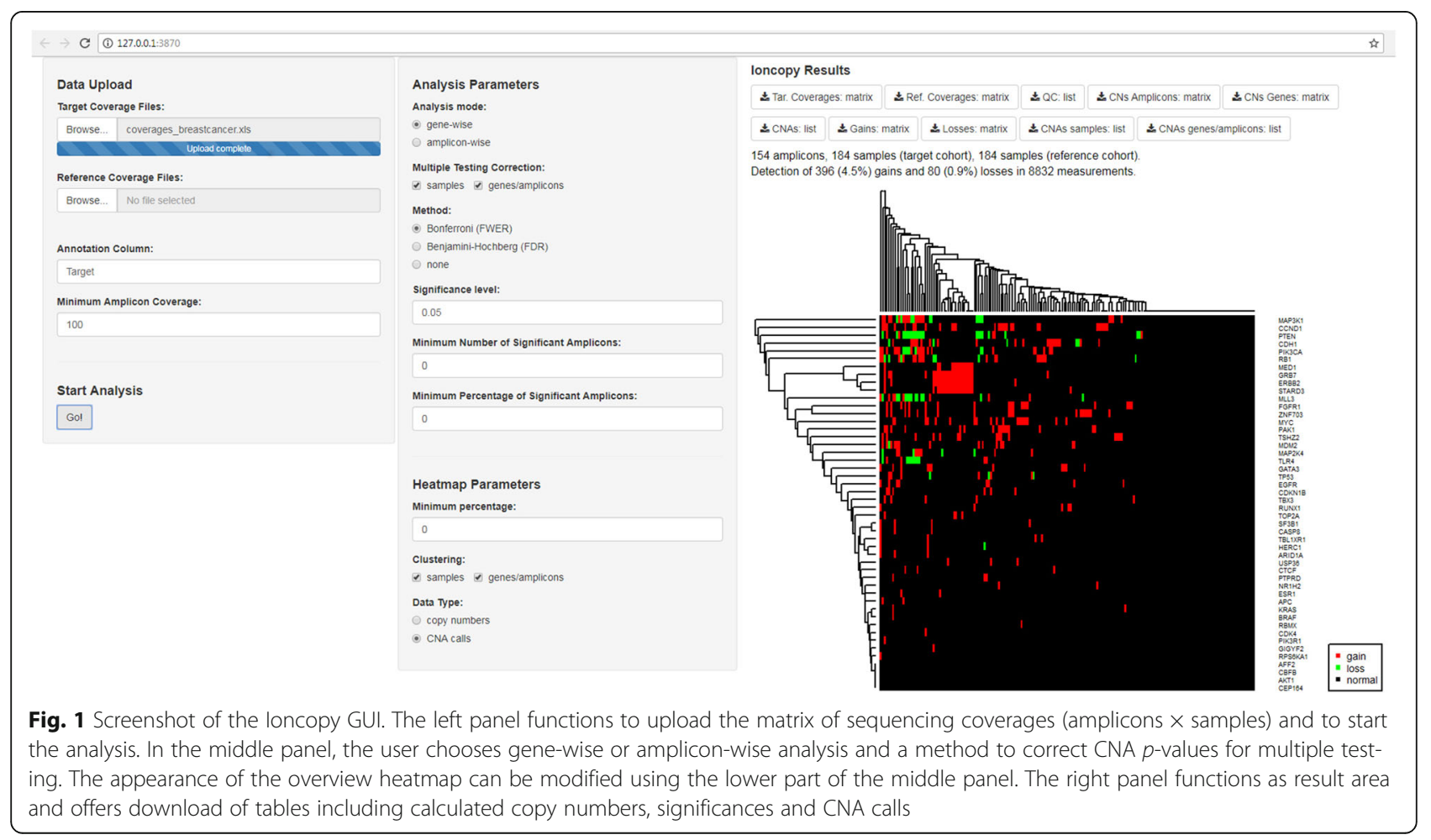




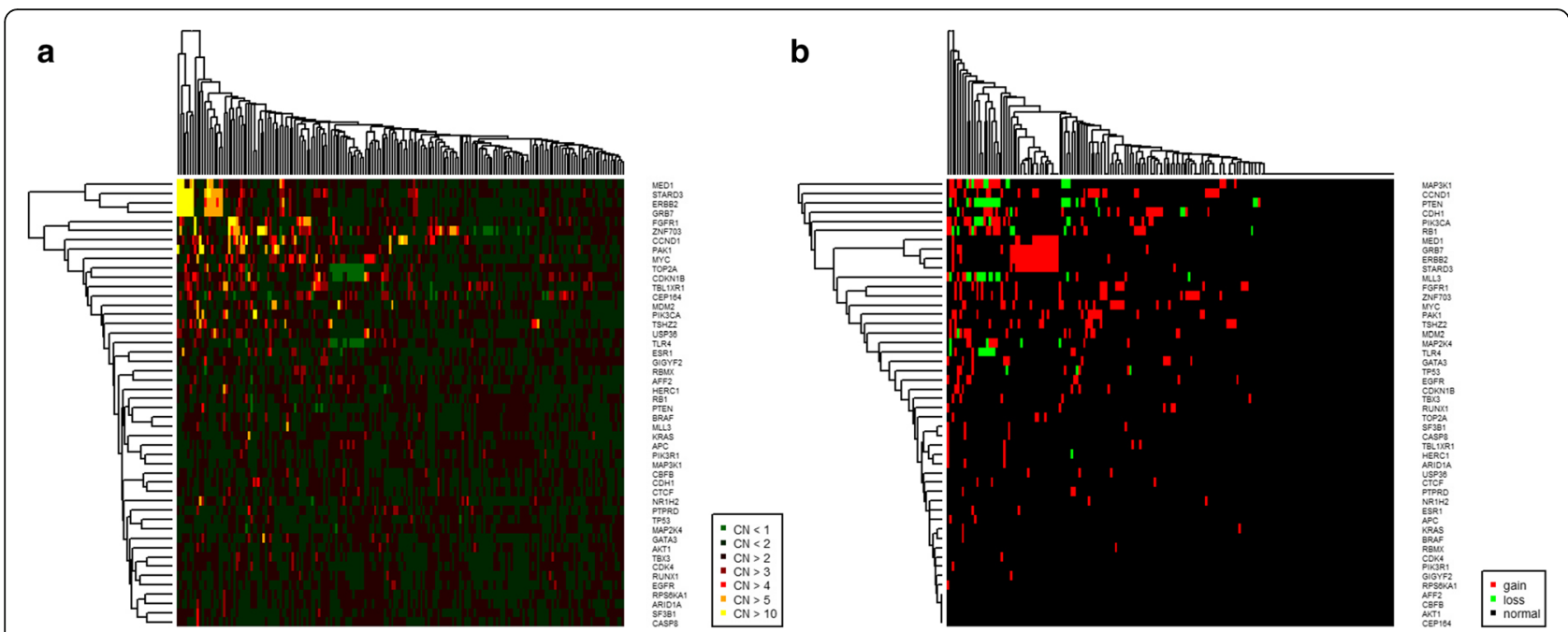

Fig. 2 Heatmaps of CN levels (a) and CNA calls (b). In both kinds of heatmaps samples and/or genes can be either left in the order of the input data or be clustered. Sparing sample clustering can be helpful for technical quality control and exclusion of batch effects

coverage matrix of the breast cancer cohort (Additional file 2) is uploaded as target coverage file. Upload of a reference coverage matrix is optional and left out here. After hitting "Go!" Ioncopy estimates CNs and significances of CNAs for each gene in each sample. In the middle panel of the GUI, it can be chosen to perform the analysis either amplicon-wise or gene-wise. Multiple testing corrections and CNA calling can be performed in a more or a less stringent ways. In the gene-wise mode, the user can chose to call only CNAs that are supported by two or more calls of amplicons or by $50 \%$ (or another selectable percentage) of the amplicons located in the gene under consideration.

Operating Ioncopy in the gene-wise analysis mode, 396 (4. $5 \%)$ gains and 80 losses $(0.9 \%)$ are detected for FWER control at $p=0.05$ taking into account multiple testing for both genes and samples. Out of these, $351(4.0 \%)$ gains and $59(0$. $7 \%$ ) losses are supported by calls of at least two amplicons. The analysis mode of FWER control can be relaxed to FDR control at 5\%, which leads to detection of $856(9.7 \%)$ gains and 295 (3.3\%) losses. Also, it is possible to run Ioncopy without multiple testing corrections, which is recommendable only for usage as search test together with validation of CNA candidates by an independent confirmatory test.

Called CNAs can be downloaded as matrix genes $x$ samples, as gene-focused list or as sample-focused list. The latter includes IGI as a sample quality measure that is calculated from the $\mathrm{CNs}$ as described in the Implementation section. High IGI corresponding to inconsistency of $\mathrm{CNs}$ within genes and inferior coverage data quality, which is often detected in samples with low DNA quality (data not shown).

Heatmaps are generated to display the estimated $\mathrm{CNs}$ or the detected CNAs (Fig. 2). In the breast cancer data,
ERBB2, GRB7, STARD3 and MED1, all located in the chromosomal region $17 \mathrm{q} 12$ and typically co-amplified in HER2+ breast cancer, cluster tightly together. Several options are available to influence the appearance of the heatmaps. For example, sample clustering can be spared to preserve the natural order of the input data what can be helpful for technical quality control and exclusion of batch effects.

A limitation of NGS based CNA detection is tumor purity, as detection sensitivity decreases significantly when the tumor cell content falls below 50\% [8]. For low tumor content samples, spatial-dissolved assays such as FISH should be preferred for CNA detection instead of bulk tissue based detection methods.

\section{Conclusions}

Ioncopy is a freely available and easy-to-use method for calling CNAs from targeted NGS data.

\section{Availability and requirements \\ Project name: Ioncopy.}

Project home page: https://cran.r-project.org/ package=ioncopy

Operating system: Platform independent.

Programming language: $R$ Shiny.

License: GNU GPL 3.

Restrictions to use by non-academics: none.

\section{Additional files}

Additional file 1: loncopy user manual. Comprehensive description of the input file format, of the analysis parameters and of the format of the output files. (PDF $1690 \mathrm{~kb}$ )

Additional file 2: Breast cancer example data set. Coverage matrix of 152 amplicons (48 genes) in 184 breast cancer samples. (XLS 196 kb) 


\section{Abbreviations}

CN: Copy number; CNA: Copy number alteration; FDR: False discovery rate; FWER: Family-wise error rate; IGI: Intra-gene inconsistency

\section{Acknowledgments}

We would like to thank the two anonymous reviewers for their comments, which helped to improve the presentation of the software in the manuscript.

\section{Funding}

The study was funded by the German Cancer Consortium (grant to CD) and by the German Cancer Aid (grant TransLUMINAL-B to CD). The funding body did neither contribute to the design of the study nor to collection, analysis and interpretation of the data nor to writing of the manuscript.

\section{Availability of data and materials}

The breast cancer data presented as use case are available in the extdata directory of the loncopy R package.

\section{Authors' contributions}

JB conceived the loncopy method for calling CNAs and implemented it in R. ER contributed to software implementation as R Shiny app and to data analysis. NP, VE, AS and CD contributed to refinement of the loncopy method and to the discussion of the results. JB worked out the critical revision of the manuscript and the software with contributions by ER. All authors approved the final version of the manuscript.

\section{Ethics approval and consent to participate}

Generation and analysis of the data presented as use case was approved by the ethics board of the Charité Hospital (Reference number EA1/139/05 Amendment 2008).

\section{Competing interests}

The authors declare that they have no competing interests.

\section{Publisher's Note}

Springer Nature remains neutral with regard to jurisdictional claims in published maps and institutional affiliations.

\section{Author details}

${ }^{1}$ Institute of Pathology, Charité Universitätsmedizin Berlin, Berlin, Germany ${ }^{2}$ Institute of Pathology, Technical University Munich (TUM), Munich, Germany. ${ }^{3}$ Institute of Pathology, University Hospital Heidelberg, Heidelberg, Germany. ${ }^{4}$ German Cancer Consortium (DKTK), Berlin, Munich and Heidelberg partner sites, Germany.

Received: 16 January 2018 Accepted: 16 April 2018

Published online: 24 April 2018

\section{References}

1. Romond EH, Perez EA, Bryant J, Suman VJ, Geyer CE Jr, Davidson NE, TanChiu E, Martino S, Paik S, Kaufman PA, et al. Trastuzumab plus adjuvant chemotherapy for operable HER2-positive breast cancer. N Engl J Med. 2005;353(16):1673-84.

2. Takezawa K, Pirazzoli V, Arcila ME, Nebhan CA, Song X, de Stanchina E, Ohashi K, Janjigian YY, Spitzler PJ, Melnick MA, et al. HER2 amplification: a potential mechanism of acquired resistance to EGFR inhibition in EGFRmutant lung cancers that lack the second-site EGFRT790M mutation. Cancer Discov. 2012;2(10):922-33.

3. Bean J, Brennan C, Shih JY, Riely G, Viale A, Wang L, Chitale D, Motoi N, Szoke J, Broderick S, et al. MET amplification occurs with or without T790M mutations in EGFR mutant lung tumors with acquired resistance to gefitinib or erlotinib. Proc Natl Acad Sci U S A. 2007;104(52):20932-7.

4. Helsten T, Elkin S, Arthur E, Tomson BN, Carter J, Kurzrock R. The FGFR landscape in Cancer: analysis of 4,853 tumors by next-generation sequencing. Clin Cancer Res. 2016;22(1):259-67.

5. Nakayama T, Toguchida J, Wadayama B, Kanoe H, Kotoura Y, Sasaki MS. MDM2 gene amplification in bone and soft-tissue tumors: association with tumor progression in differentiated adipose-tissue tumors. Int J Cancer. 1995;64(5):342-6.

6. Forschner A, Niessner $\mathrm{H}$, Moller $\mathrm{Y}$, Horak P, Frohlich M, Warsow G, Stenzinger A, Frohling S, Glimm H, Klumpp B, et al. Genomics of immunotherapy-associated Hyperprogressors-letter. Clin Cancer Res. 2017; 23(20):6374-5.

7. Endris V, Penzel R, Warth A, Muckenhuber A, Schirmacher P, Stenzinger A, Weichert W. Molecular diagnostic profiling of lung cancer specimens with a semiconductor-based massive parallel sequencing approach: feasibility, costs, and performance compared with conventional sequencing. J Mol Diagn. 2013;15(6):765-75.

8. Budczies J, Pfarr N, Stenzinger A, Treue D, Endris V, Ismaeel F, Bangemann $\mathrm{N}$, Blohmer JU, Dietel M, Loibl S, et al. loncopy: a novel method for calling copy number alterations in amplicon sequencing data including significance assessment. Oncotarget. 2016;7(11):13236-47.

9. Pfarr N, Penzel R, Endris V, Lier C, Flechtenmacher C, Volckmar AL, Kirchner M, Budczies J, Leichsenring J, Herpel E, et al. Targeted next-generation sequencing enables reliable detection of HER2 (ERBB2) status in breast cancer and provides ancillary information of clinical relevance. Genes Chromosomes Cancer. 2017;56(4):255-65.

10. Ross DS, Zehir A, Cheng DT, Benayed R, Nafa K, Hechtman JF, Janjigian YY, Weigelt B, Razavi P, Hyman DM, et al. Next-generation assessment of human epidermal growth factor receptor 2 (ERBB2) amplification status: clinical validation in the context of a hybrid capture-based, comprehensive solid tumor genomic profiling assay. J Mol Diagn. 2017;19(2):244-54.

11. Hoogstraat M, Hinrichs JW, Besselink NJ, Radersma-van Loon JH, de Voijs CM, Peeters T, Nijman IJ, de Weger RA, Voest EE, Willems SM, et al. Simultaneous detection of clinically relevant mutations and amplifications for routine cancer pathology. J Mol Diagn. 2015;17(1):10-8.

12. Pritchard CC, Salipante SJ, Koehler K, Smith C, Scroggins S, Wood B, Wu D, Lee MK, Dintzis S, Adey A, et al. Validation and implementation of targeted capture and sequencing for the detection of actionable mutation, copy number variation, and gene rearrangement in clinical cancer specimens. J Mol Diagn. 2014;16(1):56-67.

13. Grasso C, Butler T, Rhodes K, Quist M, Neff TL, Moore S, Tomlins SA, Reinig $\mathrm{E}$, Beadling $\mathrm{C}$, Andersen $\mathrm{M}$, et al. Assessing copy number alterations in targeted, amplicon-based next-generation sequencing data. J Mol Diagn. 2015;17(1):53-63.

14. Pfarr N, Penzel R, Klauschen F, Heim D, Brandt R, Kazdal D, Jesinghaus M, Herpel E, Schirmacher P, Warth A, et al. Copy number changes of clinically actionable genes in melanoma, non-small cell lung cancer and colorectal cancer-a survey across 822 routine diagnostic cases. Genes Chromosomes Cancer. 2016;55(11):821-33.

15. Oliveira C, Wolf T. CNVPanelizer: reliable CNV detection in targeted sequencing applications. R package version 1.8.0. 2016; https://bioconductor. org/packages/CNVPanelizer.

16. Budczies J, Romanovsky E. loncopy: calling copy number alterations in amplicon sequencing data. R package version 2.0.1. 2017; https://cran.rproject.org/package=ioncopy

17. Fisher RA. Statistical methods for research workers. Edinburgh: Statistical Methods for Research Workers; 1925.

\section{Ready to submit your research? Choose BMC and benefit from:}

- fast, convenient online submission

- thorough peer review by experienced researchers in your field

- rapid publication on acceptance

- support for research data, including large and complex data types

- gold Open Access which fosters wider collaboration and increased citations

- maximum visibility for your research: over $100 \mathrm{M}$ website views per year

At BMC, research is always in progress.

Learn more biomedcentral.com/submissions 